\title{
Ciberpolítica y ciberdemocracia. Una arqueología del prefijo ciber
}

\section{Cyberculture and cyberdemocracy.}

An archeology of the cyber prefix

(D) Natalia Angulo Moncayo

natalia.angulo.m@hotmail.com

Universidad Central del Ecuador (Quito)

http://orcid.org/0000-0002-9293-1448

DOI: https://doi.org/10.32719/26312514.2020.3.2

\section{Resumen}

Este ensayo, que proviene de una tesis doctoral sobre cultura digital y comunicación, establece delimitaciones conceptuales relacionadas con la política en el marco de los prefijos ciber y tecno, determinando el campo de acción de acuerdo con precisiones terminológicas, por lo que abre una discusión sobre cómo las etiquetas determinan los horizontes de comprensión de la participación política, la incidencia y la democracia en el entorno online.

\section{Abstract}

This essay, which is derived from a doctoral dissertation on digital culture and communication, outlines conceptual boundaries that are related to politics, focusing on two prefixes: cyber and techno, determining the area of action in following with terminological refinements. It then delves into a discussion on how labels determine the scope of comprehension relating to political participation, impact, and democracy in an online environment.

\section{Palabras clave • Keywords}

Cibercultura; ciberdemocracia; cibernética; ciberpolítica; comunicación política Cyberculture; cyberdemocracy; cybernetics; cyber policy; political communication

\section{Nota:}

Este trabajo proviene de la tesis titulada "El rostro del ciudadano 2.0: las ficciones de la conversación y la participación política en medios sociales, a partir de la construcción de una tipología de usuarios de Twitter en la cuenta de Rafael Correa, expresidente de Ecuador". Universidad Nacional de Cuyo-Mendoza, Argentina. 


\section{Introducción}

Pensar la democracia bajo el paraguas de lo ciber la impregna de una suerte de confusión-contradicción, sobre todo porque este concepto se torna sospechoso si es visto solo desde su potencial democratizador en función de su articulación con la tecnología. Definiciones como ciberpolítica y ciberdemocracia tomaron prestadas funciones y atribuciones de los desarrollos teóricos y prácticos del offline sin cuestionar el no lugar donde residen. Recientemente, en diálogo con expertas en temas de cultura digital, saltó un hecho que preocupa a la comunidad académica y que tiene que ver con la informalidad con la que se relacionan la democracia y la política online: la gestión de información y difusión de opiniones en redes sociales. De ahí precisamente el reto de armar, conceptualmente, una discusión sobre sus alcances, ruidos y limitaciones.

Se pretende, en primer lugar, presentar una discusión a partir de los prefijos tecno y ciber en función del sufijo política. Esto podría parecer poco útil a efectos de necesidades más urgentes sobre lo político en la web; sin embargo, no hay que olvidar que las plataformas web llevan consigo una carga simbólica que incide en las distintas dimensiones socioculturales. Además, al hablar de tecnopolítica y de ciberpolítica o estamos hablando de lo mismo o estamos frente a ámbitos completamente diferentes que no podemos distinguir. De ahí la importancia de clarificarlo.

\section{Antecedentes}

¿De dónde han salido todas las opciones de consultoría y asesoría comunicacional con objetivos solamente enfocados en ganar seguidores y reducir los costos de una política cara a cara? De ahí, precisamente, viene la "mala fama" de la comunicación política como herramienta funcional de sujetos político-partidistas que trabajan desde los modelos propagandísticos y del marketing electoral en el entorno digital y fuera de este.

Este ejercicio de diferenciación teórica y pragmática conduce a una reflexión necesaria sobre las prácticas participativas y democráticas en la web más allá del voto transparente digital y los chats públicos en medios sociales, que se han posicionado como una característica fundamental, quizá la única en ciertos ámbitos, para referirse a la participación y a la democracia en la red.

Acá más bien interesa discutir otros aspectos, incómodos, por cierto, para la corriente tecnofílica, debido a que se configura un análisis crítico sobre el control como práctica habitual e inmanente de las plataformas web, plataformas que a su vez son pensadas y controladas por grupos de poder que pusieron en marcha formas disimuladas de saturación y explotación de nuevas personas trabajadoras del espacio online, y también nuevas formas discrecionales para acceder a la información de mercados a través de los llamados "mercados de conversaciones" e interacciones virtuales. 
Esto nos obliga a pensar en una noción más que en un concepto de ciudadanía, que funciona por fuera de los marcos legales. Fue necesario girar el timón hacia un campo en tensiones y disputas de sentido para construir esta noción de ciudadanía a partir de las reflexiones sobre la preindividuación e individuación.

\section{Tecnopolítica o ciberpolítica (volcarse hacia la conflictividad)}

Las discusiones y apuestas son numerosas y las aproximaciones definitorias también lo son: desde sus raíces etimológicas, desde sus principios tradicionales; así como desde los estudios que posibilitaron entenderla como ciencia o aproximarse a ella desde las teorías, desde las relaciones o desde las comparaciones. Si de abordajes se trata, queda claro, al menos inicialmente, que, cuando se habla de política, hay entradas que implican un doble ejercicio: por un lado, asimilar distintas definiciones situadas, y por otro, deshacernos de los preconceptos que existen alrededor de la política.

Según Hannah Arendt $(2001,11)$, “preguntas tan elementales y directas como ¿qqué es la política?' pueden surgir solo si ya no hay o no son válidas las respuestas formuladas por la tradición". Este último enunciado es fundamental para este estudio, pues pensar la política desde lo ciber, probablemente implique un ejercicio de despojo de afirmaciones previas, más que de adopción de alguna o varias, precisamente porque, en la línea de Fernández Savater, la política "como palabra nombraba el horizonte de sentido que hacía relevante la vida” $(2015,101)$.

Cuando se asocia el concepto de la política a los temas inherentes al buen gobierno, en donde la relación persona-ciudad (comunidad) se da en función de la noción de bien común, a través de la acción de un gobierno que propende a la justicia social, nos estaríamos colocando desde las raíces platónicas y aristotélicas del concepto mismo, raíces que, en sus desarrollos posteriores, presentan algunas dificultades a la hora de contar con una visión más compleja, inacabada y menos determinista de la política: en primer lugar, la visión de la política enfocada a las acciones políticas de los gobernantes, que establece la vinculación del término exclusivamente con el campo gubernamental y, en segundo lugar, las relaciones adjetivadoras y por ende subjetivas de lo político en la política. Este último enunciado es de Chantal Mouffe $(2013,16)$ de quien se toma la diferenciación ontológica y óntica de la política: "Con 'lo político' me refiero a la dimensión ontológica del antagonismo, y con 'la política' me refiero al conjunto de prácticas e instituciones cuyo objetivo es organizar la coexistencia humana. Sin embargo, estas prácticas siempre operan dentro de un terreno de conflictividad influido por 'lo político"'.

Sobre el tema de investigación, nos interesa analizar la relación entre política, sociedad y poder, principalmente desde la tradición estatista y cratológica, para partir hacia la conceptualización de la ciberpolítica y la ciberdemocracia, entendiendo que la política tiene amplia capacidad de maniobra semántica y es definida, además, desde el sitio, el espacio y la praxis desde la cual se la nombra. 
De acuerdo con Fernández Savater $(2015,102)$ "la política se vino abajo como respuesta, como solución, como mundo concreto de referencia, pero persiste como pregunta, tan abierta como una herida". Así, la política está sujeta a distintas entradas hermenéuticas, sobre todo desde los estudios sobre la consecución, distribución y ejercicio del poder (enfoque cratológico) que no actúa en oposición del enfoque estatista weberiano, puesto que la política siempre va a guardar relación con la aspiración de participar o influir en el poder desde el Estado.

A efectos de lo dicho, el poder puede ser visto como recurso o resultado. Recurso en la medida de posesión efectiva a cargo de instituciones o clases determinadas; poder monopolizado y elitista, por ende, limitado, o de plano negado para otros grupos. Estos temas fueron estudiados por Hobbes, Mills y Marx, entre otros, a quienes les preocupaba, profundamente, la distribución inequitativa del poder y sus medios.

A diferencia, el poder pensado como producto de una relación no puede poseerse, sino que resulta de las relaciones que se configuran a manera de estratagemas. Se trata de un poder situado, en la medida que cada persona y agrupación se moviliza y acciona para ubicarse en una mejor posición de poder; temas estudiados principalmente por Maquiavelo, Dahl y Foucault, para quienes era fundamental analizar, no solo quien ostenta el poder, sino las prácticas políticas dadas, las relaciones y los dispositivos para conseguirlo.

Desde cualquiera de las dos perspectivas, el poder es constitutivo de las sociedades y de sus niveles de conflicto. Es decir, a través de la consecución, distribución y ejercicio del poder se instauran distintos mecanismos de vigilancia y control social que no provendrían únicamente del Estado y de sus instituciones o de la fuerza pública, sino de otras actorías y de otros sectores, igualmente capaces de maniobrar y controlar los modos de acción a través de los discursos, las regulaciones y los imaginarios que se instalan.

Figura 1. La política y su relación con la sociedad y el poder

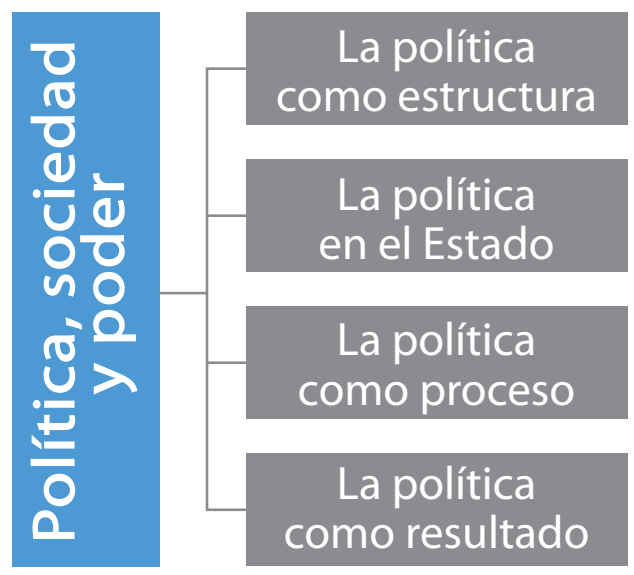

Fuente: Josep Vallés 2006. Ciencia Política, una introducción. 
En este esquema de relaciones, cuatro serían las definiciones clásicas de la política según Joseph Vallés: a) la política como mecanismo de control, propuesta, principalmente por Maquiavelo, Dahl y Lasswell, para quienes lo político es lo que ejerce dominio sobre personas y recursos; b) la política desde el enfoque estatista (institucional), con Weber a la cabeza de esta definición, para quien la política está vinculada a toda actividad autónoma de cualquier comunidad o agrupación que busca el poder político.

Desde un enfoque institucional, el Estado sería el único que podría validar sus prácticas reguladoras de dominación para gestionar los conflictos e instalar sus proyectos a lo largo de la historia; c) la política como sistema de valores, con Aristóteles, Tomás de Aquino, Locke, Parsons y Easton entre sus representantes; y d) la política como medida de protección, con Spencer, Gumplowicz y Schmitt como parte de sus defensores, este último más proclive a la visión de la política como el campo de disputa entre "nosotros-ellos" y entre el "amigo-enemigo".

Hermann Heller $(2000,22)$ señaló que la política puede ser vista como ciencia en la medida "que es capaz de ofrecernos una descripción, interpretación y crítica de los fenómenos políticos que sean verdaderas y obligatorias". En ese sentido, la política sería una actividad autónoma de organización del modo de vida y de cooperación, de un grupo social en un territorio dado. Otro punto importante es que Heller diferencia la actividad política y la actividad estatal, porque hay actividades del Estado que no son políticas y ciertas actividades políticas de grupos que no provienen del Estado.

Esta visión, de poder exclusivo e institucionalizado, es criticada por la corriente que ve otras formas de actividad política que existieron y existirán por fuera de las estructuras. En esta línea, la política, como ciencia, parte de los estudios de la conducta humana desde las reflexiones sobre "los procesos vitales de los sistemas políticos" (Easton 1973), en que el poder no estaría dado a partir de la intención de influir en la institucionalidad, sino de operar en el sistema.

Poder y conflicto están relacionados en la medida en que las distintas fuerzas políticas deben tomar decisiones y adoptar mecanismos de gestión de la conflictividad entre grupos opuestos y, para ello, se requerirá de la instalación de valores, que provienen de ideologías en tensión y en donde "las interacciones constituyen la unidad básica de análisis" (Easton 1973, 78) en el estudio de la vida política.

Desde esta perspectiva, ya podemos establecer un primer punto de partida cuando pensamos la ciberpolítica en el marco de la relación entre la sociedad de red de información y comunicación ubicua y el poder o la legitimad ganada en el mundo online. Pero, además, pensando en las cuatro definiciones de Vallés, el modelo predominante con el que se aborda la ciberpolítica parecería ser el estatal.

En ese caso, el gobierno electrónico y el gobierno por resultados (GPR) enfocan su actividad al control de la implementación de las políticas, programas y proyectos estatales, a través de plataformas informáticas que monitorean las actividades de las entida- 
des públicas y el cumplimiento de hitos específicos. En Ecuador, la experiencia tiene sus inicios, precisamente, en el gobierno de Rafael Correa, en que las instituciones públicas gubernamentales debían responder a una planificación que era monitorizada por personas a través de un sistema informático a manera de semaforización, que iba mostrando los avances, retrocesos o estancamientos en el desarrollo de los programas de gobierno.

Sin embargo, no se trata de cuestionar el modelo estatista de la política, sino de ubicarlo en su contexto específico y en el momento histórico en el que tuvo y tiene lugar, incluso en esta época cuando no solamente en Ecuador se hizo necesario aplicar un modelo de administración de la política pública, de acuerdo con el gran proyecto político de los gobiernos de turno.

Entonces, cuando hablamos de ciberpolítica, parece tratarse de un neologismo popular que vemos en los medios de información, que escuchamos en la clase política y el mundo de la consultoría política. Sin embargo, académicamente, el término todavía incomoda. Ciertamente ciber y política parecen estar asociados a través de la mediación tecnológica, desde una función eficientista y utilitarista, pero la ciberpolítica está relacionada con la noción de control y operación de la política desde, para y en un campo donde confluyen personas, máquinas, tecnologías y técnicas en aparente igualdad y aparentemente enfocadas al bien común.

A partir de ello, entonces, la ciberpolítica deja vacíos que vale la pena ir llenando, porque, como señala Ramón Cotarelo $(2013,15)$, lo que ha cambiado con el uso de las TIC no es la política en sí misma, sino los modos en que se acciona a través de estas:

El empleo de uno u otros medios ejerce una gran influencia sobre la forma en que se manifiestan los conflictos concretos, individuales, muchas veces como dilemas morales que obligan a enfrentarse a situaciones nuevas. En el caso de la ciberpolítica, el volcado en la red de la actividad de prácticamente todas las instituciones públicas, así como de las empresas de los partidos, las asociaciones, las iglesias, etc. hace que haya cambiado notablemente la relación de los ciudadanos con las administraciones, con las instituciones políticas, con los partidos políticos, las de estos entre sí y por supuesto, muy especialmente con el sector social que más se ha visto revolucionado con la red, esto es con los medios de comunicación.

La ciberpolítica se convierte en mecanismo y se apalanca en la noción de servicio público, se configura a partir de redes sociales offline que gestionan y acopian información aparentemente útil para la ciudadanía; sin embargo, la ciberpolítica, a partir de sus orígenes, construye una plataforma desde la cual operan distintas fuerzas, no solamente estatales, que buscan controlar discursos, ideologías y acciones, conduciendo a formas de operación más individuales, y homogeneizando las prácticas de grupos y comunidades, a través de distintas figuras de atención y satisfacción de necesidades. En la lógica misma de mercado, la ciberpolítica adopta tecnologías funcionales a través distintas operaciones interactivas, que generan la sensación de participación y mayor democracia, afirmaciones que se problematizarán en las siguientes páginas. 
En este marco de reflexión, la tecnopolítica parece encontrar una salida menos incómoda cambiando de prefijo, pero no necesariamente de principios. Y esa fisura, de hecho, puede ser la respuesta al interrogante ¿ciberpolítica o tecnopolítica? Porque el hecho de que no se haya dicho mayor cosa al respecto de una diferenciación marcada, al menos conceptualmente, nos hace desconfiar de la existencia de una indivisión. Inicialmente, los estudios sobre tecnología, ciencia y cultura dieron como resultado varias apuestas teóricas y metodológicas sobre la implicación de la tecnología en la cultura a manera de nuevos moldes. Es decir que la cultura, vista desde y con tecnología, construye nuevos sentidos y nuevas formas de intercambio social.

Partamos de entender el término de tecnociencia. Para Michael Menser y Stanley Aronowitz $(1998,23)$, "este juego de palabras no resuelve nada y lo complica todo". En esa línea nos dicen que la tarea de separar lo tecnológico de lo humano es casi imposible, sobre todo desde la afirmación de que "habitamos la tecnología y ella nos habita", pero además nos relaciona. En ese sentido, la tecnociencia pone el acento en el uso de tecnologías y en el estudio de los objetos culturales tecnológicos capaces de modificar, deconstruir o indeterminar las culturas o, dicho de otro modo, la tecnociencia permite entender a los grupos sociales y sus culturas a través de sus objetos culturales y sus sistemas tecnológicos. Señalan que: no obstante, debemos tener cuidado al hablar en estos términos, ya que las culturas y las tecnoculturas construyen los espacios de modos diferentes. Es decir, el espacio (tanto como concepto mítico-científico-filosófico, cuanto material, territorio en el que se vive) es un producto cultural moldeado por los seres humanos, las tecnologías y la misma tierra (Menser y Aronowitz 1998, 27).

Entonces, ¿cómo describir los alcances de la tecnopolítica? Los nudos con la ciberpolítica parecen cada vez más difíciles de desatar; sin embargo, podríamos decir, preliminarmente, que es válido entender la cultura política de la clase política y de determinados grupos sociales a través de los artefactos de los que se valen para operar. Esta afirmación inicial podría, aunque no necesariamente, ejercer una función adjetivadora, sino delimitadora, más conflictiva incluso, porque al parecer se puede hablar de tecnopolítica y ciberpolítica como vinculantes y no similares o excluyentes. En este sentido cabe la posibilidad de entender esta vinculación a partir de las reflexiones sobre la tecnopolítica desde lo óntico, lo pragmático y lo fenomenológico, es decir, lo que son, lo que hacen y como inciden en la vida cotidiana de las personas y sus subjetividades políticas.

Ariel Vercelli (2004) señala que lo ciber se construye como forma regulada y reguladora que determina el entorno digital que nos rodea. En ese sentido dijo que "las nuevas regulaciones logran fundirse con el diseño de los entornos digitales y comienzan a gobernar las conductas y los espacios en internet a través de un nuevo arte regulativo" (12). Por eso, cuando hablamos del prefijo ciber, a diferencia del prefijo tecno, los alcances de los estudios superan la visión meramente descriptiva y funcional. Porque, como señala Bruno Latour $(2007,18-9)$, el problema no es el tratamiento "de la naturaleza o 
el conocimiento, de las cosas en sí, sino de su inclusión en nuestros colectivos y en los sujetos".

Es entonces fundamental estudiar la tecnología no como cosa dada, ni como cosa creada, ni como cosa funcional, sino por su impacto en el moldeado de las interacciones, de las que hablaba Easton, y su expansión a través de técnicas de apropiación y amplificación de los discursos en el juego del poder, en un universo cuyo espesor está dado por la complejidad misma de quienes intervienen en él a través de sus subjetividades.

Este ejercicio de "redefinición" de los contextos y las personas, siguiendo a Latour, nos lleva a pensar en una suerte de polisemia alrededor de la ciberpolítica, que tampoco puede estudiarse como un modo de operar específico y que ciertamente toma prestadas las tradiciones conceptuales y pragmáticas de la política offline, pero que se vuelve innombrable y difícil de caracterizar si se estudia, más a detalle, la naturaleza de la tecnología como cosa y el contexto en donde se filtra.

La ciberpolítica y la tecnopolítica entonces, así como encuentran la forma de diferenciarse, comparten también "controlatorios" autodeformantes (Deleuze 1999). En esta lógica, tanto lo ciber como lo tecno, vendrían a ser parte de un nuevo proyecto de sociedades en las que no es necesario volver a empezar porque nunca se termina nada. El código y la contraseña se vuelven indispensables para transitar de un espacio a otro y volver las veces que sea necesario. Una especie de password que nos permiten vivir de acuerdo con los nuevos espacios de interacción y, sin él, nos quedamos al margen de vivir determinadas experiencias e historias. Este movimiento ondulatorio lo alteró todo, desde las formas de intercambio económico, hasta las formas de intercambio social:

Las antiguas sociedades de soberanía operaban con máquinas simples, palancas, poleas, relojes; las sociedades disciplinarias posteriores se equiparon con máquinas energéticas, con el riesgo pasivo de la entropía y el riesgo activo del sabotaje; las sociedades de control actúan mediante máquinas de un tercer tipo, máquinas informáticas y ordenadores cuyo riesgo pasivo son las interferencias y cuyo riesgo activo son la piratería y la inoculación de virus. (Deleuze 1999, 252)

Para las sociedades del control, la mutación es efectiva, eficiente a los intereses del capital que configuró un mercado de productos y servicios "a la medida" y ahora incluso un mercado de interacciones en el que la ciberpolítica y la tecnopolítica encuentran su razón de ser. Como bien señaló el autor, el mercado se conquista cuando se controla; así entonces, este mal llamado mercado de interacciones se conquista por parte de quienes controlan las redes y las conexiones, la conectividad y por ende las informaciones que circulan y los discursos que tienen lugar en el ciberespacio. 
Si el marketing es el alma de las sociedades de control, entonces no es para sorprenderse cuando escuchamos que el modelo predilecto de la comunicación política sea precisamente el del marketing electoral y el propagandístico (Achache 2012). Experiencias y emociones venden y modulan nuestros actos como sujetos sociales determinados por nuestra naturaleza, nuestra cultura y por nuestras tecnologías. Sociedades de control de corta duración, con contenidos que caducan cada vez más rápido en sociedades que ejercen su control a cielo abierto. La crisis de las instituciones no se debe únicamente a problemas de adaptación con el nuevo modelo de sociedad, sino con las formas de resistencia a los mecanismos de control. Eso es lo que está en juego, las formas de resistir o de actuar desde el margen.

Cuanto más pequeño se vuelve el mundo como resultado del efecto relativista de las telecomunicaciones, se produce un tipo de violencia concertada, con el riesgo de una crisis económica y social que sería simplemente la extensión de la caída visual de este "mercado de lo visible", en el que burbuja virtual de los mercados financieros (interconectados) es nada más que la consecuencia inevitable de esa burbuja visual, de una política que se ha convertido en ambos, panóptico y cibernético (Virilio 2000, 67).

¿Se puede hablar de una ciberpolítica ideal? En principio no; sin embargo, esta pregunta encuentra otro nivel de problematización. Recordemos que, como dice Foucault, el poder no existe sin las formas que puedan hacerle contrapeso. Entonces, efectivamente existe futuro para la ciberpolítica, pensada por fuera del modelo estatista, pero con sus riesgos, porque, el ciberespacio no necesariamente es conversacional ni democrático y muchas veces termina reproduciendo o configurando mecanismos de control al interior de las mismas agrupaciones que juraron combatirlo.

\section{Ciberdemocracias: el control y la distribución del poder}

Hace un poco más de 10 años, Manuel Castells lanzaba una pregunta conflictiva: “¿Habremos llegado al fin del Estado-nación?”. Esta pregunta partía de pensar que la década de los noventa marcó varios hitos en términos de inserción de nuevas tecnologías, se amplió la conectividad y aparecieron nuevas formas de asociación entre las organizaciones estatales y no estatales, a escala local, regional y mundial, lo que dio como resultado que los procesos sociales y las políticas públicas ya no se planificaran, no se decidieran, ni se monitorearan desde el Estado-nación, como único y absoluto ente controlador, lo que evidenció, por ejemplo, que la Unión Europea sea el referente más interesante, en esa época, en términos de alianzas y defensa de los intereses de los Estados.

Los grandes problemas planetarios, tales como el medio ambiente, los derechos humanos, el desarrollo compartido, se abordan en foros internacionales como las Naciones Unidas $y$, crecientemente, en organizaciones no gubernamentales: Greenpeace o Amnistía Internacional han hecho mucho más por nuestro mundo que cualquier asamblea de Estados. (Castells 1997, 2) 
Si bien todo modelo entra en crisis y se enfrenta a momentos de inevitables cambios y adaptaciones, lo cual nos vuelve al panorama absolutamente entrópico, no es menos cierto que hemos partido hacia formas distintas de gestionar lo público con un factor que permanentemente remueve los tableros políticos: las técnicas y tecnologías de información y comunicación.

Este ensayo, de ninguna manera es una exaltación a las TIC, sino más bien un punto de partida para entender a qué nos referimos cuando intentamos descifrar si la web es o no un espacio que facilita procesos más democráticos.

Si el final de algo pudiera ser absolutamente descriptible y determinante, como en este caso el Estado-nación, podría decirse que sus mecanismos de operación tradicionales han desaparecido, pero no es así. Esta estructura política puede haber cambiado de modos, pero no de esencia. En palabras de Castells (1997, 3), "no estamos ante el fin del Estado, ni siquiera del Estado nación, sino ante el surgimiento de una forma superior y más flexible". Este concepto de Estado red es cuestionable en la medida que la descentralización y la participación también son herramientas discursivas políticas del modelo tradicional y, sobre todo, porque quienes tienen el control de la conectividad mantienen prácticas desiguales de su distribución.

En el marco de lo dicho, Franco Berardi (2010) afirma que esta misma sociedad red o "revolución red", como él la llama, se reafirma en la tecnología a partir de una visión "felicista" que ve una oportunidad, más que una desventaja y desde ahí han sido construidos los imaginarios sobre la cibercultura, la inteligencia colectiva y la dinámica colaborativa en redes. Lógicamente hay experiencias interesantes y muy positivas en términos de tecnología, sociedad y democracia participativa o deliberativa, pero no dejan de ser eso, experiencias.

A Giovanni Sartori (1987) le preocupaba más reflexionar sobre lo que no es democracia y preguntarse cuánta democracia se tiene. A partir de esas premisas, primero establece una separación con el precedente de los griegos y, en segundo lugar, insiste en que la democracia es inalcanzable, instalada como valor o como ideal supremo, base de toda lucha, en donde esa condición de inalcanzable es precisamente lo que le permite su subsistencia.

Aparecen entonces, en el marco de las democracias contemporáneas, la mayoritaria y la de consenso, que trasladadas al campo online obligan a mirar con atención las posibilidades y los desafíos de democracias conectadas en contraste con sus versiones análogas. Las nuevas formas de distribución del poder y el control a través de las TIC son materia de análisis en un momento político en el que las formas centralizadas y descentralizadas, si bien no han encontrado su total finitud, sí se enfrentan a un modo de operación distinto conforme funcionan sus tecnologías pensando que "el diagrama del protocolo pasó de la red centralizada a la descentra- 
lizada y ahora finalmente a la red distribuida. Las redes distribuidas no tienen cadena de mandos, solo agentes autónomos que operan siguiendo reglas del sistema "científicas" y "preacordadas" (Galloway 2010, 6).

El foco de discusión, entonces, es analizar las formas en las que se ejerce control y cómo se distribuye el poder en los distintos grupos sociales a través de diversas tecnologías ¿Quiénes distribuyen este poder? Una pregunta compleja de desmenuzar, pero a la vez obvia en su generalización. Los medios sociales de acceso gratuito no son gratuitos y las plataformas pensadas para la participación no son participativas porque regulan y se autorregulan, establecen algoritmos que generan sensación de empatía, recreando las formas más básicas de interacción social cara a cara.

En este juego de relaciones, hay por lo menos una premisa interesante que no se encuentra inserta en el funcionamiento de la plataforma informática, sino en el acto discursivo y en los juegos de verdad (Foucault) o prácticas de libertad alrededor de la garantía que supone un proceso democrático a través de medios tecnológicos.

En 2017, por ejemplo, se vivieron las elecciones presidencias y de asambleístas en Ecuador. Lo cierto es que estaba previsto que los resultados se entregaran, mediante el software implementado, en un tiempo récord, comparado con los métodos tradicionales y los sistemas de información. Los resultados tardaron en promedio una semana más y los datos se volvieron poco confiables, lo que tornó poco confiable al proceso electoral y democrático en sí mismo.

Así como los sistemas políticos no centralizados y descentralizados, los sistemas políticos distribuidos pueden configurar ambientes violentos y desarrollar sus formas de control, incluso sus propios mecanismos de afectación emocional y domesticación. Es necesario señalar rápidamente que, si bien de a poco, van automatizándose una buena parte de gestiones del servicio público, aún existe un esquema en que la repetición, la burocracia y el caos forman parte de un proceso no consensuado de digitalización de lo público, pues "lo que nos interesa aquí no es solamente la descripción fenomenológica de esta evolución, sino el método empleado" (Lazzarato 2006, 81). El sistema actual está pensado para forzarnos a encarar, de manera abrupta, los nuevos procedimientos y requerimientos del Estado y sus instituciones, sin que ello implique bienestar, comodidad y eficiencia, tal como se venden estos imaginarios en el mercado de imaginarios de la propaganda política, que frecuentemente nos hace pensar, con bastante alivio, que nos encontramos en sistemas más abiertos y más eficientes si las tecnologías están presentes.

Las decisiones parecen ser consensuadas y se crean plataformas para generar la sensación de escucha. La democracia parece un accesorio indispensable en el discurso y en la legitimación del sistema de gobierno con el apoyo de formas democráticas online. Pensemos por un momento en los trámites interminables, que además de hacerse "vía web" deben formalizarse in situ, en las mismas dependencias públicas y privadas. De hecho, las instituciones privadas son las que menos incurren, en Ecuador, en la digitalización de sus 
procesos. Las aseguradoras, por ejemplo, aún trabajan de manera personal o las empresas telefónicas, aún demandan la presencia de la persona interesada para dar paso a las gestiones.

\section{Conclusiones}

Las tecnologías analógicas como la radio, televisión y prensa, por su esquema y funcionamiento, establecen esquemas de comunicación unidireccionales, mientras que las tecnologías digitales, como los ordenadores y la tecnología móvil, incorporan un esquema de comunicación dialógico y multidireccional.

El storytelling es una técnica que permite contar historias a partir de medios electrónicos, lo que posibilita el empleo de una comunicación multidireccional y un modelo educativo, abierto, flexible, dinámico, que se basa en el aprendizaje vivencial, experiencial y de contenido emocional. Los relatos digitales, que son otra forma de referir a la categoría anglicista del storytelling, permiten, tanto en la comunicación como en la educación, transmitir ideas mientras se generan vínculos con los espectadores, las audiencias, a la vez que se construye mensajes de manera colectiva y conectada.

La emergencia de la cultura de la convergencia de medios ha permitido la inclusión de los viejos con los nuevos medios, donde el storytelling ya no solo se presenta como narrativas multimediales en canales de videos, sino que hace uso de la nueva ecología de medios como blogs, wikis, LMS, CMS y redes sociales, permitiendo que el mensaje se expanda y llegue a más audiencias.

Las tendencias en la comunicación y la educación en la actual era digital, indican que en el paso de la web 2.0, a la web 3.0 y la web 4.0, los relatos, contenidos e información ya no se presentan solo en los ordenadores, sino en tecnologías móviles. Así también logra hibridar la realidad física con la realidad virtual que está dando el paso de una inteligencia colectiva hacia una inteligencia artificial, que favorece la implantación de esquemas de la comunicación, ubicuos, permanentes y cocreativos.

\section{Referencias}

Achache, Giles. 2012. "El marketing político". En Comunicación política: construcción de un modelo, coordinado por Arnaud Mercier, 49-62. Buenos Aires: La Crujía.

Arendt, Hannah. 2001. ¿Qué es la política? Barcelona: Paidós.

Aronowitz, Stanley y Michael Menser. 1998. "Sobre los estudios culturales, la ciencia y la tecnología” En Tecnociencia y cibercultura: La interrelación entre cultura, tecnología y ciencia, compilado por Staley Aronowitz, Barbara Martinsons y Michael Menser, 00-00. Barcelona: Paidós.

Berardi, Franco. 2010. Generación post-alfa: patologías e imaginarios del semiocapitalismo. Buenos Aires: Tinta Limón. 
Castells, Manuel. 1997. “¿Fin del Estado-nación?”. El País (España), 26 de octubre.

Cotarelo, Ramón. (ed.). 2013. Ciberpolítica: Las nuevas formas de acción y comunicación políticas. Valencia: Tirant Humanidades.

Deleuze, Gilles. 1999. “Posdata sobre las sociedades de control” En El lenguaje libertario, compilado por Christian Ferrer, 115-21. Buenos Aires: Altamira.

Easton, David. 1997. Enfoques sobre teoría política. Buenos Aires: Amorrortu.

Fernández-Savater, Amador. 2015. “Crisis de la presencia: Una lectura desde Tiqqun”. En Caja Negra Fanzine (4): 101-22.

Galloway, Alexander. 2007. “Acción del juego, cuatro momentos”. Artnodes (7): 23-42.

Heller, Hermann. 2000. Teoría del Estado. Ciudad de México: Fondo de Cultura Económica (FCE).

Latour, Bruno. 2007. Nunca fuimos modernos. Buenos Aires: Siglo XXI.

Lazzarato, Miguel. 2006. "Los conceptos de vida y de vivo en las sociedades de control". En Políticas del acontecimiento, de Miguel Lazzarato. Buenos Aires: Tinta Limón.

Mouffe, Chantal. 2013. Agonística: Pensar el mundo políticamente. Buenos Aires: FCE.

Sartori, Giovanni. 1987. Teoría de la democracia. Madrid: Alianza.

Vallés, Josep. 2006. Ciencia política: Una introducción. Barcelona: Ariel.

Vercelli, Ariel. 2004. La conquista silenciosa del ciberespacio: Creative commons y el diseño de entornos digitales como nuevo arte regulativo en Internet. Buenos Aires: Ariel Hernán Vercelli.

Virilio, Paul. 2000. The Information Bomb. Londres: Verso. 